\title{
Mediação de conflitos sociais, polícia comunitária e segurança pública
}

\author{
Lilia Maia de Morais Sales ${ }^{1}$ \\ Emanuela Cardoso O. de Alencar ${ }^{2}$ \\ Gustavo Raposo Feitosa ${ }^{3}$
}

\begin{abstract}
Sumário: Introdução; 1. Polícia cidadã - fortalecendo os vínculos entre a polícia e a sociedade; 1.1. Práticas de polícia cidadã Brasil; 2. A mediação de conflitos; Conclusão; Referências.
\end{abstract}

\begin{abstract}
Resumo: Entre as medidas que estão sendo pensadas na atualidade para diminuir os índices de violência e aumentar a segurança, destaca-se a proposta da polícia comunitária, que é um modelo de polícia preventiva que objetiva aproximar os policiais da população e fortalecer a confiança da sociedade nas instituições policiais do Estado. Este modelo objetiva assegurar maior legitimidade social para o desenvolvimento do
\end{abstract}

\begin{abstract}
Among the efforts that are being thought to reduce violence and to increase public security, the communitarian policy proposal is being distinguished as a model of preventive policy that objectives to approach the police to the population and to fortify the confidence of the society in State police institutions. This model aims
\end{abstract}

1 Advogada possui Doutorado em Direito pela Universidade Federal de Pernambuco (2003), mestrado em Direito pela Universidade Federal do Ceará (2000) e possui graduação em Direito pela Universidade Federal do Ceará (1997). Atualmente é professora Titular da Universidade de Fortaleza, Coordenadora do Programa de Pós-Graduação em Direito - Mestrado e Doutorado, Professora Adjunta da Universidade Federal do Ceará, Diretora-presidente do Instituto de Mediação e Artragem do Ceará (Mediação Brasil), colaboradora como parecerista da Fundação Cearense de Apoio ao Desenvolvimento Científico e Tecnológico (FUNCAP) (2006-2008).

2 Possui graduação em Direito pela Universidade de Fortaleza (1999), mestrado em Direito Constitucional pela Universidade de Fortaleza (2007) e é aluna do Doctorado en Derechos Fundamentales de la Universidad Autónoma de Madrid, Espanha. Tem experiência na área de Direito, com ênfase em Direito Constitucional e Direitos Humanos, atuando principalmente nos seguintes temas: tráfico de seres humanos, processos migratórios, migração feminina, direitos humanos, direitos fundamentais e mediação de conflitos. É autora de artigos científicos em periódicos e obras coletivas.

3 Advogado, Doutor em Ciências Sociais pela UNICAMP. Coordenador do Núcleo de Pesquisa do Centro de Ciências Jurídicas da UNIFOR. Professor de Direitos Humanos da UNIFOR. Professor adjunto de Processo Civil da UFC. Líder do grupo de pesquisa Direito e Relações Internacionais, Segurança e Reforma do Estado. 
seu trabalho e a adesão da população como parceira na prevenção de delitos. O policiamento comunitário é um projeto que se desenvolveu nas décadas de 1970 e 1980, quando organizações policiais em diferentes países da América do Norte e da Europa ocidental começaram a promover inovações na sua estrutura e funcionamento e na forma de lidar com o problema da criminalidade. Os modelos desenvolvidos nesses países tiveram por base uma nova estrutura de polícia, orientada para um novo modelo de policiamento mais voltado para a comunidade. Aliado à proposta de aproximar os agentes de segurança pública e a população, os centros de mediação nasceram destinados a auxiliar a resolução de conflitos sociais frutos da convivência de pessoas que têm vínculos afetivos e relações continuadas (familiares, vizinhos, amigos) e que, quando mal administrados, podem gerar atos de violência e crime. Em Fortaleza, os dados do CIOPS revelam que, em média, a metade das ocorrências de conflitos interpessoais envolve pessoas com relações continuadas. A ideia da mediação ligada aos agentes da segurança pública é inovadora porque, além de contribuir para aproximá-los da população, contribui para as atividades do policiamento comunitário, na medida em que pode bem administrar diversos conflitos sociais e auxiliar no desenvolvimento da cultura da paz. A polícia comunitária está assim inserida na proposta da Secretaria Nacional de Segurança Pública, do Ministério da Justiça, de construção de uma segurança cidadã, que objetiva, de um lado, o trabalho integrado da polícia e da comunidade, e de outro, a contenção e a prevenção da violência.

Palavras-chave: segurança pública; polícia comunitária; mediação de conflitos. to assure greater police social legitimacy and to estimulate the perception of population as partner to delicts prevention. The communitarian policing is a project that was developed between the decades 1970 and 1980, when police organizations, in different countries of North America and Occidental Europe, started to promote innovations on its structure and functioning and on its ways to deal with the problem of crime. Ally to the proposal to approach the public security agents to population, the mediation centers were created destined to assist the social conflict resolution. Those conflicts, when badly managed, can generate acts of violence and crime. In Fortaleza, the data of CIOPS (Security Information Center) discloses that, on average, half of the occurrences about interpersonal conflicts involves 1people with continued relations. The idea about mediation being done by agents of the public security is innovative because, beyond contributing to approach them of the population, it contributes for the activities of the communitarian policing and the conflicts resolution. The communitarian policy is also inserted in the proposal of the National Secretariat of Public Security, of the Ministry of Justice as a way to integrated the policy and the community and to prevent violence.

Keywords: public security; communitarian policy; conflict; mediation.

\section{Introdução}

O Brasil observa na atualidade um agudo quadro de conflitos sociais que se estende por diferentes esferas. Áreas urbanas e rurais, bairros de diferentes classes e também escolas estão sendo palco de agressões físicas e psicológicas quase diárias, gerando uma sensação de insegurança e revolta na população do país. Alega-se que o problema é agravado pela erosão das instituições que são responsáveis pela formação dos cidadãos e pela segurança de todos. A família, a escola, os órgãos de segurança pública, entre outros, são sempre citados por estarem falhando no cumprimento de suas funções sociais. 
Paralelo ao problema da violência que se agrava periodicamente, as autoridades, cobradas pela sociedade, implementam meios repressivos com o objetivo de tentar conter a onda de agressividades que parece incontrolável. As cidades passaram a ser monitoradas por sistemas de fiscalização eletrônica; a polícia está presente nas ruas, mas nem sempre consegue o apoio da população (que muitas vezes não confia e tem medo de seus membros); as escolas estão sendo vigiadas por meios eletrônicos, protegidas por cercas eletrônicas e detectores de metal (mas as agressões continuam a ocorrer entre os próprios atores escolares, como professores e alunos). Assim, apesar dessas medidas de vigilância, a violência continua presente e noticiada pela imprensa, tornando urgente a criação de alternativas inovadoras que possam melhor administrar os conflitos existentes.

\section{Polícia cidadã - fortalecendo os vínculos entre a polícia e a sociedade}

As Polícias, Militar e Civil, órgãos do Estado responsáveis pelo policiamento repressivo e preventivo, e demais agentes de segurança pública, muitas vezes encontram dificuldades no desenvolvimento de seu mister em face do medo e da desconfiança, fruto de atos de corrupção ou de ações violentas e desastrosas. Esta barreira invisível criada entre os membros da segurança pública e a população dificulta a cooperação para a realização de denúncias e para o bom desenvolvimento de ações de segurança que objetivem prevenir e reprimir a violência.

O estigma negativo (polícia violenta, corrupta, autoritária) que acompanha a ação dos policiais contribui para criar barreiras de comunicação e confiança entre esses profissionais e a população (COSTA, 2004).

A percepção negativa da população sobre as instituições policiais e a maneira como essas efetivamente atuam no cumprimento de suas funções encontram raízes profundas na história nacional, com impactos de difícil superação até os dias de hoje. As polícias brasileiras nasceram distantes do que atualmente se pode considerar como a função policial na preservação da segurança pública. Presas, em grande medida ao modelo bélico destinado à atuação em conflitos armados, como as revoltas ocorridas ao longo do período imperial ou às exigências de 
controle político e social, as polícias civil e militar espelhavam em suas organizações as necessidade de estruturas sociais violentas, desiguais e autoritárias associadas à escravidão.

Para Holloway (1997), "a polícia era um exército permanente travando uma guerra social contra adversários que ocupavam o espaço a seu redor". O uso de uma instituição militarizada se justificaria pela necessidade de "concentrar, regular e dirigir forças contra o inimigo", que não deveria ser exterminado, mas subjugado. No caso específico das polícias militares, a opção pela estrutura militarizada durante o período regencial decorreu da necessidade de dispor de instrumentos para o disciplinamento de uma corporação composta de homens pobres, mal remunerados e sem qualquer forma de qualificação profissional. No quadro geral das profissões oferecidas a um homem livre no Império, o serviço militar no Exército e a atuação como policial representavam as opções com as menores remunerações. O nascente Estado brasileiro aplicava a hierarquia e a disciplina militar como meio de controle rígido e violento sobre suas forças policiais.

Some-se a esta necessidade de controle interno das corporações, a exigência imediata de atuar em situações de guerra no instável contexto de consolidação nacional. Seja para o combate de revoltas populares, tentativas de secessão, movimentos de escravos, seja por ameaças externas, recorreu-se sistematicamente às polícias militares como extensão de um ainda incipiente exército nacional. Todavia, esta força, estruturada em moldes militares, encontrava-se submetida ao poder das elites provinciais e precisava conciliar as demandas bélicas com o controle social de pobres e escravos.

O advento da República e as diversas mudanças políticas e sociais ocorridas em cerca de dois séculos não foram, contudo, suficientes para superar o modelo militarizado, criado para uma realidade vinculada a outros pressupostos. As transformações empreendidas gradualmente ao longo das décadas nas polícias militares garantiram maior grau de profissionalização e especialização, permitiram a criação de uma carreira, a padronização do seu funcionamento no território nacional e a concentração no policiamento ostensivo.

Não obstante, a atuação das polícias militares continuou marcada pela sua fidelidade às autoridades estaduais e aos grupos políticos no poder, 
o que explica a sua permanência como uma das mais antigas e estáveis instituições brasileiras. Toda esta situação, reafirmada e fortalecida ao longo dos séculos XIX e XX, imerge o policial dos dias de hoje num conjunto contraditório de demandas com as quais ele não consegue lidar. Se, por um lado, participa-se de uma corporação rigidamente hierarquizada, fechada, pouco transparente e ainda presa a práticas nascidas para uma realidade política e social excludente e autoritária, por outro, cresce a exigência de uma polícia que respeite direitos, negue privilégios sociais e mostre eficiência e eficácia sem abusar da violência.

A redemocratização pôs em evidência a importância de transformar práticas estatais anteriormente aceitas: todavia, muitas vezes, os policiais não vivenciaram em seu cotidiano, dentro e fora da corporação, uma realidade que lhes permita vislumbrar uma nova forma de fazer polícia. Ao mesmo tempo, não somente as modificações políticas do país, como a própria realidade do crime e da violência revelam a importância de competências pouco valorizadas tradicionalmente num policial. O desafio de enfrentar desde conflitos familiares e disputas entre vizinhos até ações armadas de poderosas organizações criminosas expõe a dificuldade em conciliar soluções capazes de abranger a reforma das instituições policiais, o respeito aos direitos fundamentais e a mudança nos paradigmas que regem relação entre a polícia e o cidadão.

Bengochea et al. (2004) questionam a possibilidade de uma polícia diferente em uma sociedade democrática. Para eles, essa possibilidade passa por alguns eixos: por mudanças nas políticas de qualificação profissional, por um programa de modernização e por processos de mudanças estruturais e culturais que discutam questões centrais para as polícias, como as relações com a comunidade, contemplando o espaço das cidades; a mediação de conflitos do cotidiano como o principal papel de sua atuação; e o instrumental técnico e valorativo do uso da força e da arma de fogo.

No modelo tradicional de polícia, a força tem sido quase o único instrumento de intervenção, sendo usada frequentemente de forma não profissional e desqualificada, às vezes até à margem da legalidade. Para se ter um outro modelo de polícia, é preciso centrar sua função na garantia e efetivação dos direitos fundamentais do cidadão e na interação com a comunidade, estabelecendo a mediação e a negociação como instrumentos principais. 
Para os autores:

No momento em que começa a existir essa transformação política e social, a compreensão da sociedade como um ambiente conflitivo, no qual os problemas da violência e da criminalidade são complexos, a polícia passa a ser demandada para garantir não mais uma ordem pública determinada, mas sim os direitos, como estão colocados na constituição de 88. Nesse novo contexto, a ordem pública passa a ser definida também no cotidiano, exigindo uma atuação estatal mediadora dos conflitos e interesses difusos e, muitas vezes, confusos. Por isso, a democracia exige justamente uma função policial protetora de direitos dos cidadãos em um ambiente conflitivo. A ação da polícia ocorre em um ambiente de incertezas, ou seja, o policial, quando sai para a rua, não sabe o que vai encontrar diretamente; ele tem uma ação determinada a fazer e entra num campo de conflitividade social. Isso exige não uma garantia da ordem pública, como na polícia tradicional, sustentada somente nas ações repressivas, pelas quais $\mathrm{o}$ ato consiste em reprimir para resolver o problema. O campo de garantia de direitos exige uma ação mais preventiva, porque não tem um ponto determinado e certo para resolver. (BENGOCHEA et al., 2004).

A sociedade é complexa e nela ocorrem conflitos de diversas naturezas, que, em função dessas diferenças, reclamam ações distintas em sua resolução. A polícia, ao utilizar um procedimento padrão, único, para a resolução de conflitos de várias naturezas, limita a efetividade de suas ações. O êxito da polícia, atuando em uma perspectiva cidadã, depende e tem como proposta desenvolver ações preventivas e atuar para contribuir na recuperação dos agentes de delitos.

\subsection{Práticas de polícia cidadã no Brasil}

Diante desse quadro, necessária se faz a implementação de ações que possam bem administrar os conflitos, que promovam uma maior integração entre a população e os órgãos de segurança e que fortaleçam a confiança da sociedade nas instituições policiais do Estado. Possibilita-se assim a promoção de maior legitimação social no desenvolvimento do seu trabalho, tornando a população parceira na prevenção de delitos. 
A polícia comunitária representa um conjunto de projetos desenvolvidos no exterior e no Brasil, objetivando uma maior aproximação das polícias com a sociedade. Trata-se de uma filosofia de policiamento desenvolvida nas décadas de 1970 e 1980, quando organizações policiais em diferentes países da América do Norte e da Europa ocidental começaram a promover inovações na sua estrutura e funcionamento e na forma de lidar com o problema da criminalidade. Os modelos desenvolvidos nesses países tiveram por base uma nova estrutura de polícia, orientada para um modelo de policiamento mais voltado para a comunidade (MESQUITA NETO, 2004).

Quatro inovações são consideradas essenciais para o desenvolvimento do policiamento comunitário: a organização da prevenção do crime tendo como base a comunidade; a reorientação das atividades de policiamento para enfatizar os serviços não emergenciais e para organizar e mobilizar a comunidade para participar da prevenção do crime; descentralização do comando da polícia por áreas; e participação de pessoas civis, não policiais, no planejamento, execução, monitoramento e/ ou avaliação das atividades de policiamento (MESQUITA NETO, 2004).

Além desses, são apontados quatro fatores importantes para a implantação e consolidação do policiamento comunitário (MESQUITA NETO, 2004): o envolvimento enérgico e permanente do chefe com os valores e implicações de uma polícia voltada para a prevenção do crime; motivação dos profissionais de polícia por parte de seu chefe; defesa e consolidação das inovações realizadas; e apoio público, da sociedade, do governo e da mídia.

Ante as potencialidades do policiamento comunitário e os resultados das experiências já existentes, a Secretaria Nacional de Segurança Pública, do Ministério da Justiça (SENASP, 2007), com o apoio do Programa das Nações Unidas para o Desenvolvimento - PNDU, desenvolve, desde 2007, o Curso Nacional de Promotor de Polícia Comunitária, que se dirige a líderes comunitários e membros da segurança pública. $\mathrm{O}$ curso objetiva transmitir lições de segurança pública, mobilização social, estruturação de conselhos comunitários, bem como aulas sobre direitos humanos, relações interpessoais e mediação de conflitos.

Segundo o Ministério da Justiça (SENASP, 2007), a polícia comunitária trabalha em conjunto com a população e as instituições de 
segurança pública e defesa social. O objetivo é que todos juntos tenham condições de identificar, priorizar e resolver problemas relativos à criminalidade, para garantir qualidade de vida aos brasileiros. Nesse projeto, os próprios moradores tornam-se coresponsáveis pela segurança pública no local em que residem, contribuindo para a concretização do dispositivo constitucional que diz que a segurança pública é dever do Estado, direito e responsabilidade de todos (CF, art. 144).

Diversos estados brasileiros estão desenvolvendo ações com a filosofia da polícia comunitária. No Amapá (FRANÇA, 2007), a ideia da polícia cidadã vem sendo realizada desde 1995, com a implementação do Programa de Desenvolvimento Sustentável, no qual está inserido o Programa Polícia Cidadã.

Em 2000, a Polícia Militar de São Paulo criou a Comissão Estadual de Polícia Comunitária e o Departamento de Polícia Comunitária e Direitos Humanos, com o objetivo de aperfeiçoar e intensificar o processo de implantação do policiamento comunitário no estado (MESQUITA NETO, 2004).

O Ceará também desenvolve políticas nesse sentido. Além de estar inserido no Curso Nacional de Promotor de Polícia Comunitária, o estado, por meio da Secretaria de Segurança Pública e Defesa Social - SSPDS (2007), desenvolve, dentro do Projeto Ceará Seguro, a revitalização dos Conselhos Comunitários de Defesa Social - CCDS, por meio do qual objetiva a aproximação com a comunidade, na busca de uma parceria responsável, concidadã, em que todos somem esforços e compartilhem responsabilidades e solidariedade, em benefício da ordem pública e do convívio social sadio.

Uma outra tecnologia social que objetiva a aproximação de agentes de segurança pública e a população é a criação de centros de mediação destinados a auxiliar na resolução de conflitos sociais, nos quais atuam como mediadores desses conflitos tanto policiais como membros da sociedade. Esses atores são capacitados em mediação e atuam em conjunto nos centros, contribuindo para diminuir o estigma negativo que às vezes macula a imagem dos policiais (agressivo, violento, corrupto), e aproximá-los da população, na medida em que, como mediadores, serão escolhidos pelas pessoas para mediar os seus conflitos. 
A mediação destaca-se como importante meio para bem administrar os conflitos que surgem nas comunidades, eis que, em alguns municípios, como é o caso de Fortaleza, as estatísticas revelam que a maior parte dos conflitos registrados se referem a conflitos sociais.

Os dados do Centro Integrado de Operações de Segurança - CIOPS (2007), na capital cearense, comprovam essa assertiva ao apresentar os números dos casos que mais são denunciados pela população. Analisando as estatísticas das ocorrências registradas em relação ao que foi identificado como briga de família e embriaguez e desordem, em 2001, o somatório dessas ocorrências alcançou 33.270 casos e, em 2002, 36.510 casos registrados, o que representou mais que a soma dos crimes contra a pessoa e o patrimônio.

A partir de 2004, as estatísticas do CIOPS incluíram ainda as ocorrências relacionadas à desordem, desvinculadas do uso de bebidas alcoólicas. Assim, seus relatórios mostraram que, em 2004, foram registrados 42.192 casos de desordem $(22,02 \%), 27.823$ denúncias de briga de família $(14,52 \%)$ e 20.986 casos de embriaguez e desordem $(10,95 \%)$.

Em 2005, os registros da instituição revelaram que ocorreram 48.611 casos de desordem $(25,72 \%), 28.383$ casos de briga de família $(15,01 \%)$ e 20.070 casos de embriaguez e desordem (10,61\%). Em 2006, as estatísticas registraram 48.518 casos de desordem (25,65\%), 26.050 casos de briga de família $(13,77 \%)$ e 18.861 casos de embriaguez e desordem $(9,97 \%)$.

Os tipos de conflitos apresentados pelos levantamentos estatísticos do CIOPS mostram que, em média, a metade dos casos que geram as ocorrências policiais se caracteriza por serem conflitos de caráter social. Tais conflitos caracterizam-se por envolver pessoas com vínculos afetivos e relações continuadas (famílias, vizinhos, colegas) que, por não conseguirem dialogar para bem administrar os problemas vividos, transformam discussões em agressões ou até em crimes.

A existência de centros de mediação nas comunidades e a capacitação adequada de policiais em mediação de conflitos, atuando inclusive como mediadores, contribui para que esses profissionais possam identificar situações dessa natureza e encaminhá-los aos centros, nos quais 
as partes terão a oportunidade de dialogar de forma pacífica a divergência vivida e buscar construir a melhor resolução para o caso.

A ideia da mediação ligada à segurança pública revela-se inovadora, pois, além de contribuir para aproximar os policiais da população, melhora as atividades do policiamento comunitário (na medida em que pode bem administrar os conflitos mais comuns sujeitos à intervenção policial) e auxilia no desenvolvimento de uma cultura de Paz.

A mediação contribui ainda para a resolução dos conflitos daqueles que possuem relações continuadas, que, quando mal administrados, podem gerar violências. Isso porque nos novos espaços criados para a realização de mediações, oferecem-se aos moradores dos bairros beneficiados atividades de capacitação para agirem como mediadores. Esses habitantes, bem como os agentes de polícia que lá atuam, conhecem as dinâmicas sociais do local e os principais conflitos e problemas que enfrentam, o que possibilita uma visão mais ampla do contexto no qual a violência ocorre.

\section{A mediação de conflitos}

Há mais de três décadas, vêm sendo desenvolvidos no Brasil projetos que tencionam implementar a mediação de conflitos (SALES, 2004; SALES, 2007; SIX, 2001; MORAIS, 1999; VEZZULLA, 1998) como meio que objetiva não apenas auxiliar a boa resolução de litígios entre as partes envolvidas, mas bem administrar as relações existentes, para que as pessoas mantenham seus vínculos afetivos e possam construir uma sociedade fundada numa cultura de paz.

A mediação é um procedimento consensual de resolução de conflitos por meio do qual uma terceira pessoa imparcial, escolhida ou aceita pelas partes age para encorajar e facilitar a resolução dos problemas. As pessoas envolvidas no conflito constroem a decisão que melhor as satisfaça. A mediação representa, assim, um mecanismo de solução de litígios utilizado pelas próprias partes que, movidas pelo diálogo, encontram uma alternativa ponderada, eficaz e satisfatória. O mediador auxilia na construção desse diálogo. 
Por meio da mediação, buscam-se os pontos de convergência entre os envolvidos na contenda, que possam amenizar a discórdia e facilitar a comunicação. Muitas vezes, as pessoas estão de tal modo ressentidas que não conseguem visualizar nada de bom no histórico do relacionamento entre elas. A mediação estimula, através do diálogo, o resgate dos objetivos comuns que possam existir entre os indivíduos que estão vivendo o problema.

Na mediação, procura-se evidenciar que o conflito é natural, inerente aos seres humanos. O conflito e a insatisfação tornam-se necessários para o aprimoramento das relações interpessoais e sociais. $\mathrm{O}$ que se reflete como algo bom ou ruim para as pessoas é a administração do conflito. Se for bem administrado, ou seja, se as pessoas conversarem pacificamente ou procurarem a ajuda de uma terceira pessoa para que as auxilie nesse diálogo, será o conflito bem administrado. Se as pessoas, por outro lado, agredirem-se física ou moralmente, ou não conversarem, causando prejuízo para ambas, o conflito terá sido mal administrado. Assim, não é o conflito que é ruim; pelo contrário, ele é necessário, a sua boa ou má administração é que será positiva ou negativa.

A premissa de que o conflito é algo importante para a formação do indivíduo e da coletividade faz com que as posturas antagônicas deixem de ser interpretadas como algo eminentemente mau para se tornar algo comum na vida de qualquer ser humano que vive em sociedade. Quando se percebe que um impasse pode ser um momento de reflexão e, em consequência, de transformação, torna-se algo positivo.

Em síntese, o conflito, quase sempre tomado como algo negativo, ganha na mediação um significado positivo, natural e necessário para o aprimoramento das relações, e sua boa administração representa o caminho para o entendimento e para a harmonia entre as partes (VEZZULLA, 1999).

Por suas peculiaridades, a mediação torna-se um meio de solução adequado a conflitos que envolvam relações continuadas, ou seja, relações que são mantidas apesar do problema vivenciado. Ressalta-se, também, que os conflitos que tratam de sentimentos e situações fruto de um relacionamento - mágoas, frustrações, traições, amor, ódio, raiva revelam-se adequados à mediação. Isso porque é nesses tipos de conflitos que se encontram as maiores dificuldades para o diálogo, em virtude da 
intensidade dos sentimentos. Na mediação, há um cuidado, por parte do mediado, de facilitar esse diálogo entre as partes, de maneira a permitir a comunicação pacífica e a discussão efetiva dos conflitos (SIX, 2001).

Esse procedimento tem como um de seus principais objetivos a solução dos conflitos. Apesar de sua importância, não deve ser o único objetivo a ser perseguido na mediação de conflitos. Os outros objetivos da mediação, como a prevenção da má administração dos conflitos, que possibilita o tratamento adequado do problema e a mantença dos vínculos afetivos entre as partes é primordial, bem como a busca da inclusão social e da paz social.

Busca-se trabalhar a mediação como instrumento de promoção da paz social e de diminuição da violência. Assim, a paz social é entendida como algo que vai além da inexistência de violência física e moral, passando pela necessidade de efetivação dos direitos fundamentais. Não se alcança a paz em sociedades onde há fome, altos índices de desemprego, pessoas realizando trabalhos forçados ou em situação análoga à escravidão, exploração sexual infantil, falta de moradia, baixos níveis de educação e saúde, entre outros graves problemas sociais que interferem no desenvolvimento harmônico e sustentável da sociedade, interferindo na manutenção da paz social.

Ensina-se a paz quando se resolve e se previne a má administração dos conflitos; quando se busca o diálogo; quando se possibilita a discussão sobre direitos e deveres e sobre responsabilidade social; quando se substitui a competição pela cooperação - o perde-ganha pelo ganha-ganha.

A mediação, como forma pacífica e participativa de resolução de conflitos, exige das partes envolvidas a discussão sobre os problemas, sobre os comportamentos, sobre direitos e deveres de cada um - todo esse diálogo realizado de forma cooperativa, fortalecendo o compromisso ético com o diálogo honesto.

Como a prática da mediação estabelece a participação ativa das pessoas na solução de conflitos, passa-se a não somente discutir sobre questões individuais, mas questões de natureza coletiva também. As experiências brasileiras em mediação, especialmente aquelas realizadas nas periferias dos municípios, têm revelado mudanças de comportamento das pessoas: tornaram-se mais participativas nas decisões individuais e coletivas (luta e conquista de curso de alfabetização para adultos, cursos jurídicos, 
cursos sobre planejamento familiar, discussões sobre ressocialização da pena ao se receber para auxiliar nos trabalhos administrativos dos centros de mediação pessoas condenadas à prestação de serviços etc.).

Desta feita, a prática da mediação, por incentivar o diálogo entre partes, estimula as pessoas a debaterem não apenas os seus conflitos interpessoais, mas contribui para o empoderamento dessas pessoas a partir do momento em que se sentem sujeitos de direitos e que devem criar ferramentas sociais para reivindicar e efetivar os seus direitos garantidos pelo ordenamento.

Ademais, na medida em que se abrem espaços de diálogo, que são os locais onde se realizam as mediações, em que instituições privadas ou públicas, disponibiliza-se à sociedade mais um meio capaz e eficaz de resolução de litígios, sendo uma alternativa acessível a todos, ao invés de se buscar a autotutela (fazer justiça com as próprias mãos) ou de não buscar qualquer solução, o que só agrava o conflito.

Por sua vez, a mediação desenvolvida em bairros das cidades (mediação comunitária) propicia o diálogo entre as pessoas que convivem diariamente, auxiliando na solução dos seus conflitos e contribuindo para a construção da paz social.

Os mediadores comunitários são geralmente moradores da própria comunidade, que são capacitados por meio de cursos de mediação de conflitos e podem trabalhar voluntariamente ou não, dependendo da instituição à qual estejam vinculados.

São vários os pontos positivos da mediação, podendo-se destacar, como o estímulo ao diálogo positivo entre famílias e vizinhos; incentivo à participação ativa dos cidadãos na solução dos conflitos individuais e coletivos; criação de espaços de escuta; prevenção à má administração de conflitos futuros; destaque à valorização do coletivo em detrimento do individual, buscando sempre a solução de um problema que satisfaça todas as partes envolvidas.

A mediação comunitária tem como objetivos:

Desenvolver entre a população, valores, conhecimentos, crenças, atitudes e comportamentos conducentes ao fortalecimento de uma cultura político-democrática e uma cultura de paz. Busca ainda enfatizar a relação entre os valores e as práticas democráticas e a 
convivência pacífica e contribuir para um melhor entendimento de respeito e tolerância e para um tratamento adequado daqueles problemas que, no âmbito da comunidade, perturbam a paz (SALES, 2004).

A mediação é democrática porque estimula a participação ativa das pessoas na solução de conflitos e propicia a inclusão social quando deixa que elas busquem por elas mesmas a solução de seus problemas.

Ao mesmo tempo, a experiência do policial com a prática da mediação representa uma oportunidade para olhar, ouvir e refletir sobre a dinâmica própria da violência que aflige as populações sobre as quais esses agentes atuam. Na rotina policial, as ocorrências se sucedem e naturalizam ou banalizam os dramas, a miséria e a violência. Vítimas e agressores misturam-se numa dinâmica que abre pouco espaço para o diálogo e ou respeito. A atuação e a habilitação dos policiais como mediadores rende frutos concretos sobre os indicadores de violência e sobre a eficiência das políticas de segurança; contudo uma das suas mais promissoras contribuições consiste na possibilidade de esses homens e mulheres reconstruírem a forma de lidar com os conflitos dentro e fora da sua rotina de trabalho, reafirmando-se como cidadãos nessa nova realidade política brasileira.

\section{Conclusão}

A mediação de conflitos, incluída nos projetos da Secretaria Nacional de Segurança Pública sobre policiamento comunitário, representa mais uma ferramenta para bem administrar os conflitos sociais existentes nos bairros. A presença marcante nas estatísticas de ocorrência de conflitos, fruto da convivência de pessoas que têm relações continuadas reforça a necessidade de mecanismos para bem administrar tais situações. A mediação atua, assim, como estratégia de prevenção de violência e de atos criminosos com grande potencial para difundir uma nova cultura de paz.

A participação de policiais como mediadores, desde que bem preparados para este fim, reduz o distanciamento entre as polícias e as comunidades, além de contribuir para a redução do estigma de violência e corrupção associados aos órgãos de segurança pública. $\mathrm{O}$ potencial da 
mediação como instrumento transformador da ação policial não se limita aos seus efeitos como uma política de segurança pública, pois oferece ainda uma chance de inserir os policiais numa nova dinâmica capaz de auxiliar na transformação do papel social destes homens e mulheres e na maneira como lidam com a violência dentro e fora da sua vida profissional.

\section{Referências}

ARAÚJO, Luis Alberto Gómez. Os mecanismos alternativos de solução de conflitos como ferramentas na busca da paz. Trad. Ângela Oliveira. Mediação - métodos de resolução de controvérsias, n. 1, coord. Ângela Oliveira. São Paulo: LTr, 1999.

BENGOCHEA, Jorge Luiz Paz; GUIMARÃES, Luiz Brenner; GOMES, Martin Luiz; ABREU, Sérgio Roberto. A transição de uma polícia de controle para uma polícia cidadã. São Paulo em perspectiva, v. 18, n. 1, p. 119-131, 2004.

BRASIL. M. J. SENASP investe em capacitação de polícia comunitária. Disponível em: <http://www.mj.gov.br/>. Acesso em: 2 ago. 2007.

BRASIL. SSPDS. Projeto Ceará Seguro. Disponível em: $<$ http://www. seguranca.ce.gov.br/ politica_sspdc.jsp>. Acesso em: 2 ago. 2007.

CENTRO INTEGRADO DE OPERAÇÕES DE SEGURANÇA - CIOPS. Levantamento estatístico comparativo das ocorrências registradas nos anos de 2001 a 2006. Documento disponível nos arquivos da instituição.

FRANÇA, Cássio L. de. Policia cidadã: segurança pública. Disponível em: <http://www.dhnet.org.br/3exec/nova policia/policiacidada_ap.htm>. Acesso em: 3 ago. 2007.

GOMES, Naldson Ramos da. Ofício de polícia, violência policial e luta por cidadania em Mato Grosso. São Paulo em perspectiva. v. 18, n. 1, p. 111-118, 2004.

HOLLOWAY, Thomas H. A polícia no Rio de Janeiro - repressão e resistência numa cidade do século XIX. São Paulo: FGV, 1997. 
MESQUITA NETO, Paulo de. Policiamento comunitário e prevenção do crime - a visão dos coronéis da Polícia Militar. São Paulo em perspectiva. v. 18, n. 1, p. 103-110, 2004.

MORAIS, José Luis Bolzan de. Mediação e arbitragem - alternativas à jurisdição. Porto Alegre: Livraria do Advogado, 1999.

POLICIA CIDADÃ: segurança pública. Disponível em: $<$ http://www. dhnet. org.br/3exec/novapolicia/policiacidada_ap.htm>. Acesso em: 3 ago. 2007.

SALES, Lilia Maia de Morais. Justiça e mediação de conflitos. Belo Horizonte: Del Rey, 2004.

SALES, Lilia Maia de Morais. Mediação de conflitos. Família, escola e comunidade. Florianópolis: Conceito, 2007.

SIX, Jean-François. Dinâmica da mediação. Trad. Águida Arruda Barbosa, Eliana Riberti Nazareth, Giselle Groeninga. Belo Horizonte: Del Rey, 2001.

VEZZULLA, Juan Carlos. Teoria e prática da mediação. Curitiba: Instituto de Mediação e Arbitragem do Brasil, 1998. 